\title{
Association of myeloperoxidase gene variation with carotid atherosclerosis in patients with essential hypertension
}

\author{
JINRUI FANG ${ }^{1}$, LIYA MA ${ }^{1}$, SHUHONG ZHANG $^{2}$, YAN FANG $^{1}$, PENG SU $^{1}$ and HUIYUAN MA ${ }^{1}$ \\ ${ }^{1}$ Department of Cardiology, The Third Ward of Cadre, People's Hospital of Gansu Province; \\ ${ }^{2}$ Women's Secondary School of Gansu Province, Lanzhou, Gansu 730000, P.R. China
}

Received June 12, 2012; Accepted October 10, 2012

DOI: $10.3892 / \mathrm{mmr} .2012 .1143$

\begin{abstract}
The aim of this study was to investigate the association between myeloperoxidase (MPO) gene polymorphisms and carotid atherosclerosis (AS) in patients with essential hypertension (EH). A total of 214 patients with $\mathrm{EH}$ were divided into an AS and a non-atherosclerosis (non-AS) group. MPO gene polymorphisms in EH were detected using PCR. The frequency of increased intima-media thickness and the occurrence of plaque in the carotid artery in the AS group was higher compared to the non-AS group. The frequency of the GC genotype in the AS group was significantly higher compared to the non-AS group. The frequency of carotid AS is higher in patients with hypertension, which is related to the MPO gene polymorphism.
\end{abstract}

\section{Introduction}

Atherosclerosis (AS) is an inflammatory disease. In the disease development process, macrophages, which are cells of the immune system, are regarded as one of the inflammatory components of AS (1). Once macrophages are activated, phagocytes generate reactive oxygen species, which induce destructive oxidative stress to the vascular wall (2). In AS, chronic inflammation of the arterial wall causes an exaggerated phagocyte response and generates oxidative low density lipoprotein (LDL). LDL granules cause AS. Due to the continuous inflammation, phagocyte activity is believed to cause inflammatory reactions in the vascular wall, including cellular activation and proliferation, leading to further damage (3-6).

Myeloperoxidase (MPO) is a heme protease containing a heme prosthetic group secreted by neutrophilic granulocytes, monocytes and macrophages of certain tissues, and it is one of the heme peroxidase superfamily members (7). Nicholls and Hazen (8) found that although MPO was capable of achieving a

Correspondence to: Professor Liya Ma, Department of Cardiology, The Third Ward of Cadre, People's Hospital of Gansu Province, 204 Donggangxi Road, Lanzhou, Gansu 730000, P.R. China E-mail: liyamacn@126.com

Key words: essential hypertension, gene polymorphism, myeloperoxidase, genetic susceptibility, carotid artery ultrasound, atherosclerosis certain immune function, MPO also caused a harmful effect to the artery wall, and oxidation products generated by its catalysis and macrophages were aggregated at the AS site. Eiserich et al (9) found that MPO was rapidly absorbed by endothelial cells through the cell transformation process and aggregated in the endothelial gap, participating in the effect of nitric oxide on the vascular wall. MPO weakened the nitric oxide-dependent vasodilatation reaction, reduced bioavailability of nitric oxide in mature cells and regulated the vascular inflammatory reaction by adjusting the bioavailability of nitric oxide.

At present, it has been found that MPO is associated with the incidence of leukemia, nephritis, polyangitis, tumors and AS (10). New studies suggest that MPO is one type of inflammatory marker, and its level in plasma may predict the incidence risk of future coronary heart disease in a healthy population (11). It may also reflect the extent of heart failure severity (12) in patients with chronic heart failure and the risk of adverse cardiac events (13). With the increased amount of MPO research, it has been shown that MPO gene polymorphisms cause differences in the susceptibility of individuals to certain diseases, and that MPO is closely related to the occurrence and development process of a variety of human diseases (14). Our research found that MPO gene polymorphisms are associated with essential hypertension (EH), and this study further investigates the relationship of carotid atherosclerosis (AS) of EH patients with MPO gene polymorphisms.

\section{Patients and methods}

Patients. This study was a single center case-control study. The study participants were patients hospitalized and examined at the People's Hospital of Gansu Province (December 2007-September 2008). There were 214 cases of hypertension, including 128 male and 86 female cases. The average age of the patients was $58.96 \pm 12.92$ years. According to ultrasound findings of the common carotid artery, the patients were divided into AS and non-atherosclerosis (non-AS) groups. Hypertension diagnosis complied with the 'Chinese Hypertension Prevention and Cure Guideline in 2005', and patients with secondary hypertension, cardiomyopathy, congenital heart disease, rheumatic valvular heart disease, coronary heart disease, lung cancer, Alzheimer's disease, chronic granulomatous disease, benzolism and leukemia were excluded. This study was conducted in accordance with the declaration of Helsinki, and 
was conducted with approval from the Ethics Committee of the People's Hospital of Gansu Province. Written informed consent was obtained from all participants.

Detection of clinical biochemical indicators. Each patient fasted for $12 \mathrm{~h}$, and $3 \mathrm{ml}$ anterior cubital vein blood was drawn in the morning and placed into a dry tube. The standard ELISA method was used to detect plasma total cholesterol (TC), triglycerides (TG), high density lipoprotein (HDL) and LDL.

Color doppler ultrasoundmeasurement indicators andmethods. All patients lay on their backs, and conventional ultrasonography of the carotid artery was conducted. A ProSound $\alpha 10$ (Hitachi Aloka, Tokyo, Japan) Color Doppler ultrasound imaging instrument was used. The probe frequency was $7.5 \mathrm{~Hz}$, and axial resolution was $0.1 \mathrm{~mm}$ (15). The measured AS indicators included: intima-media thickness (IMT) detection of the common carotid artery. Longitudinal ultrasound images of the common carotid artery posterior wall showed two parallel light lines, and the distance between the two lines was the IMT of the carotid artery. Normal common carotid artery had an IMT of $<1 \mathrm{~mm}$. Determination of plaques: plaques were defined as restricted acoustic echo from the lumen, IMT $\geq 1.3 \mathrm{~mm}(16)$. Internal diameter (D) of carotid artery: the vertical distances between anterior and posterior intima surfaces at the bilateral thickest positions of IMT. The mean was obtained.

DNA extraction. A total amount of $3 \mathrm{ml}$ anterior cubital vein blood was drawn in the morning and placed into a dry tube, and anticoagulation was conducted with $2 \%$ EDTA to separate leukocytes. In addition, the conventional phenol/chloroform method was used to extract DNA.

MPO genotyping. It was necessary for this research to obtain the upstream base sequence of the MPO gene using the National Center for Biotechnology Information of America (NCBI) GenBank. Primer 5.0 software was used to design the primers with restriction sites complying with amplification. Primer sequences: upstream primer, 5'-CGG TAT AGG CAC ACA ATG GTG AG-3'; downstream primer, 5'-GCA ATG GTT CAA GCG ATT CTT C-3'. The primers were synthesized by Sangon Biotech (Shanghai) Co., Ltd. (Shanghai, China). A DNA fragment containing the AciI restriction site was amplified, and the length of the amplified DNA fragment was $350 \mathrm{bp}$. The total PCR system $(50 \mu \mathrm{l})$ included $10 \mathrm{X}$ reaction buffer $5.0 \mu \mathrm{l}, \mathrm{dNTP} 200 \mu \mathrm{mol} / 1, \mathrm{MgCI}_{2} 2.5 \mathrm{mmol} / 1$, primers $15 \mathrm{pmol}$, template $200-500 \mathrm{ng}$ and Taq DNA polymerase 1.0 units (Promega, Madison, WI, USA), respectively. Amplification parameters: predenaturation for $4 \mathrm{~min}$ at $94^{\circ} \mathrm{C}$, denaturation for $1 \mathrm{~min}$ at $94^{\circ} \mathrm{C}$, annealing for $1 \mathrm{~min}$ at $56^{\circ} \mathrm{C}$, extension for $1 \mathrm{~min}$ at $72^{\circ} \mathrm{C}$ for 35 cycles, and extension for $7 \mathrm{~min}$ at $72^{\circ} \mathrm{C}$. Subsequently, $10 \mu \mathrm{l}$ PCR product, $0.5 \mu 1$ restriction enzyme AciI (BioLab, Beijing, China), $2 \mu \mathrm{l}$ NE buffer $10 \mathrm{X}$ and $7.5 \mu 1$ sterile deionized double distilled water were digested by enzymes at $37^{\circ} \mathrm{C}$ overnight. Restriction products were electrophoresed with $2.5 \%$ agarose gel (containing $0.5 \mu \mathrm{g} / \mathrm{ml}$ ethidium bromide), and a gel imaging system was used to capture images to determine the genotypes. In this study, a total of three genotypes were detected: GG, GA and AA. For the GG genotype, the sizes of three obtained fragments following restriction with the
Table I. Comparison of MPO gene in patients with hypertension between AS and non-AS groups (n, \%).

\begin{tabular}{lccccc}
\hline Group & Case & GG & AA + GA & F-value & P-value \\
\hline AS & 172 & $\begin{array}{c}120 \\
(69.8)\end{array}$ & $\begin{array}{c}52 \\
(30.2)\end{array}$ & & \\
Non-AS & 42 & $\begin{array}{c}26 \\
(61.9)\end{array}$ & $\begin{array}{c}16 \\
(38.1)\end{array}$ & 61.56 & 0.00 \\
& & & & \\
\hline
\end{tabular}

MPO, myeloperoxidase; AS, atherosclerosis; non-AS, non-atherosclerosis.

Table II. Comparison of MPO allele between AS and non-AS groups (n, \%).

\begin{tabular}{lrrr}
\hline Group & G & A & P-value \\
\hline AS & $292(0.846)$ & $104(0.154)$ & \\
Non-AS & $68(0.768)$ & $32(0.232)$ & 0.046 \\
\hline
\end{tabular}

MPO, myeloperoxidase; AS, atherosclerosis; non-AS, non-atherosclerosis.

AciI incision enzyme were 169, 120 and 61 bp, respectively. For the GA genotype, the sizes of the four obtained fragments following restriction were 289, 61, 169 and $120 \mathrm{bp}$, respectively. For the AA genotype, the sizes of the two obtained fragments following restriction were 289 and 61 bp, respectively (Fig. 1).

Statistical analysis. The genotype distributions in all patients should comply with the Hardy-Weinberg balance. SPSS 11.0 statistical software was used, and all data were expressed as the means \pm standard deviation (means \pm SD. The homogeneity test for variance was used for data with normal distribution, t-test was used for comparison between the two groups, and one-way ANOVA was used for comparison among multiple groups. In addition, $\chi^{2}$ test of four-grid table or of paired data was used for count data. $\mathrm{P}<0.05$ was considered to indicate a statistically significant difference.

\section{Results}

Gene comparison of patients with hypertension between the $A S$ and the non-AS groups. Carotid artery intima-media thickening frequency of hypertension patients of the AS group markedly increased, and the GG genotype distribution frequency of the AS group was significantly higher compared to that of the non-AS group. There was a significant difference between the two groups $(\mathrm{F}=61.56, \mathrm{P}=0.00)$ (Table $\mathrm{I})$.

Comparison of alleles between AS and non-AS groups. For comparison of the allele frequency distribution between the AS and non-AS groups, the A allele frequency of the AS group was lower compared to that of the non-AS group, and there was a significant difference between the two groups (0.154 vs. $0.232, \mathrm{P}=0.046$ ) (Table II). 
Table III. Association of gene variation with clinical variables, such as carotid artery ultrasound in AS and non-AS groups mean $\pm \mathrm{SD})$.

\begin{tabular}{|c|c|c|c|c|}
\hline \multirow[b]{2}{*}{ Variables } & \multicolumn{2}{|c|}{ GG } & \multicolumn{2}{|c|}{$\mathrm{AA}+\mathrm{GA}$} \\
\hline & $\begin{array}{c}\mathrm{AS} \\
(\mathrm{n}=120)\end{array}$ & $\begin{array}{l}\text { Control } \\
(\mathrm{n}=26)\end{array}$ & $\begin{array}{c}\mathrm{AS} \\
(\mathrm{n}=52)\end{array}$ & $\begin{array}{l}\text { Control } \\
(\mathrm{n}=16)\end{array}$ \\
\hline BMI $\left(\mathrm{kg} / \mathrm{m}^{2}\right)$ & $24.12 \pm 2.29$ & $23.76 \pm 2.18$ & $24.31 \pm 2.66$ & $23.38 \pm 2.18$ \\
\hline SBP (mmHg) & $144.15 \pm 15.72$ & $139.16 \pm 13.97$ & $142.88 \pm 14.13$ & $143.27 \pm 14.97$ \\
\hline DBP (mmHg) & $93.83 \pm 9.70$ & $93.62 \pm 8.58$ & $94.16 \pm 11.01$ & $95.58 \pm 10.32$ \\
\hline $\mathrm{TC}(\mathrm{mmol} / \mathrm{l})$ & $5.04 \pm 0.85$ & $4.84 \pm 0.92$ & $5.10 \pm 0.95^{\mathrm{a}}$ & $4.98 \pm 0.93$ \\
\hline $\mathrm{TG}(\mathrm{mmol} / \mathrm{l})$ & $2.08 \pm 1.26^{\mathrm{a}}$ & $1.84 \pm 0.86$ & $1.98 \pm 0.86$ & $1.89 \pm 0.90$ \\
\hline HDL-c (mmol/l) & $1.39 \pm 0.30$ & $1.45 \pm 0.32$ & $1.36 \pm 0.25$ & $1.41 \pm 0.29$ \\
\hline LDL-c (mmol/l) & $3.22 \pm 0.78$ & $3.03 \pm 0.83$ & $3.27 \pm 0.84$ & $3.12 \pm 0.85$ \\
\hline $\mathrm{CCA}(\mathrm{mm})$ & $7.57 \pm 0.77^{\mathrm{a}}$ & $6.79 \pm 0.87$ & $7.09 \pm 1.30^{\mathrm{a}, \mathrm{b}}$ & $6.85 \pm 0.81$ \\
\hline IMT (mm) & $0.98 \pm 0.26^{\mathrm{a}}$ & $0.79 \pm 0.23$ & $0.97 \pm 0.17^{\mathrm{a}}$ & $0.77 \pm 0.15$ \\
\hline
\end{tabular}

${ }^{\mathrm{a}} \mathrm{P}<0.05$ vs. the normal control group; ${ }^{\mathrm{b}} \mathrm{P}<0.05$ vs. the GG genotype group. AS, atherosclerosis; non- $\mathrm{AS}$, non-atherosclerosis; $\mathrm{BMI}$, body mass index; SBP, systolic blood pressure; DBP, diastolic blood pressure; TC, total cholesterol; TG, triglycerides; HDL, high density lipoprotein; LDL, low density lipoprotein; CCA, common carotid artery; IMT, intima-media thickness.

Table IV. Comparison of carotid artery plaque between AS and non-AS groups (n, \%).

\begin{tabular}{lccrrr}
\hline Group & Case & Control & AS & F-value & P-value \\
\hline Plaque & 162 & $45(25.9)$ & $120(74.1)$ & & \\
Without & 112 & $69(61.8)$ & $43(38.2)$ & 31.804 & 0.00 \\
\hline
\end{tabular}

AS, atherosclerosis; non-AS, non-atherosclerosis.

Relationship of MPO-463G/A gene variation with internal D of the carotid artery, IMT and other clinical variables. In patients with the GG genotype, TG level, internal D of the carotid artery and IMT of the AS group were higher than those of the control group, and there were significant differences $(\mathrm{P}<0.05)$. In the AA and GA genotypes, TC, internal D of the carotid artery and IMT were higher than those of the control group, and there were differences between the 2 groups $(\mathrm{P}<0.05)$. Among different genotypes, TG level, internal D of carotid artery and IMT of the AS group were higher compared to those of the non-AS group, and there were significant differences between the 2 groups $(\mathrm{P}<0.05)$ (Table III).

Comparison of carotid artery plaque of EH patients between $A S$ and non-AS groups. The incidence rate of carotid artery plaque in the AS group significantly increased, while the incidence rate of carotid artery plaques in the AS group significantly reduced, and there was a difference between the two groups $(\mathrm{P}=0.00)$ (Table IV).

\section{Discussion}

The human MPO gene is located in q23 to q24 of chromosome 17 , containing 12 exons and 11 introns, and its length is

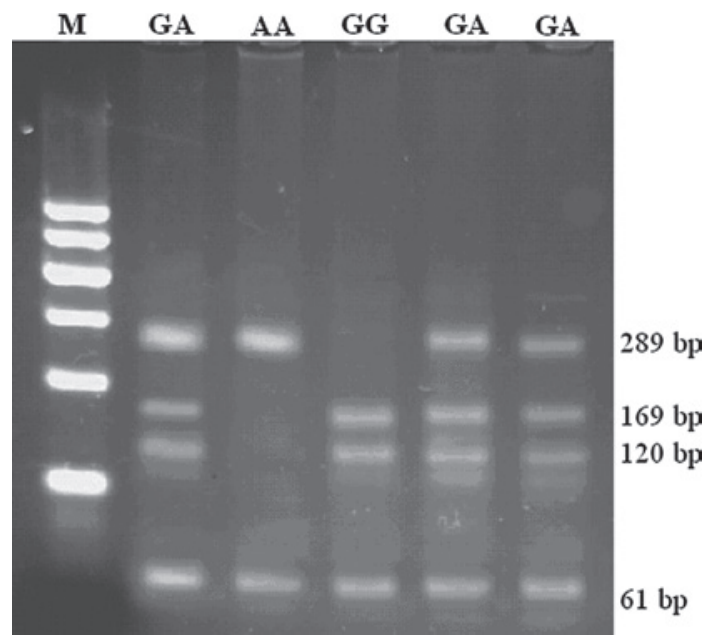

Figure 1. Myeloperoxidase (MPO)-463G/A polymorphism digested by enzymes. Genotype GG included 169, 120 and 61 bp DNA fragments; genotype GA included 289, 61, 169 and 120 bp DNA fragments; genotype AA included 289 and 61 bp DNA fragments. M, marker.

approximately $14,638 \mathrm{bp}$ and its gene expression is regulated by growth factor III. It is known that the MPO gene firstly expresses a precursor protein with a relative molecular weight of $89 \times 10^{3}$. Following translation, it is cut into $\alpha$ and $\beta$ subunits. Subsequently, the two subsets polymerize into the mature MPO molecule. After the sugar chain is bound, it finally forms functional MPO. The MPO gene DNA sequence changes due to defects of MPO during the expression process, and its activity is influenced. Polymorphisms of the MPO gene also affect the transcription and expression, and have an influence on the susceptibility of the body to a variety of diseases.

Since MPO gene polymorphisms were first reported in 1993, research on these gene polymorphisms has increased. MPO gene polymorphisms are related to the occurrence and development of a variety of diseases. Skuladottir et al (17) showed 
that the MPO gene 463G/A polymorphism AA/GA genotype was associated with a decreased susceptibility to lung cancer. Hung et al (18) found that the GG genotype was involved in the incidence of bladder carcinoma. Certain studies indicated that MPO gene polymorphisms were associated with the incidence of gastric cancer and breast carcinoma $(19,20)$. Asselbergs et al (21) reported that the patients with the G/G genotype and coronary heart disease suffered from more cardiovascular events than the patients with the G/A and A/A genotypes and suggested that the $\mathrm{G} / \mathrm{G}$ genotype coronary heart disease and family history were the main risk factors predicting cardiovascular events. Sugiyama et al (22) indicated that the pathogenic mechanism of MPO gene polymorphisms possibly lies in the fact that MPO participated in LDL oxidation, and high-level MPO increased plaque vulnerability to cause stable plaques to become instable plaques and increase AS incidence. Mäkelä et al (23) found that the MPO gene 463G/A polymorphism had an age-dependent relationship with aorta fibrous degeneration and calcified atherosclerotic disease. It was found from single factor and linear regression analyses that for males aged less than 53 years old, the MPO gene (A/A and A/G) had low expression in aorta fibrous degeneration and calcified atherosclerotic disease, while it had high expression in male patients aged 53 years or greater suffering from thoracic aorta and abdominal aorta AS. Nikpoor et al (24) observed that French Canadians more highly expressed MPO alleles G and A. It was thought that the potential role of MPO in the development of coronary arteriosclerosis possibly promoted the effect of the MPO gene 463G/A polymorphism on the incidence of coronary artery diseases. Exner et al (25) found that when the HDL level was less than $49 \mathrm{mg} / \mathrm{dl}$, MPO was associated with the occurrence of carotid AS. Hoy et al (26) reported that MPO content in plasma was not associated with the MPO gene 463G/A polymorphism, while the subjects carrying the A allele presented more high-level risk factors causing AS than the subjects carrying the $\mathrm{G}$ allele, such as serum TG, TC, LDL and apolipoprotein B. Mäkelä et al (27) reported that the MPO gene was not associated with type 2 diabetes mellitus. In the control group, the comparison result of carotid artery IMT showed that the MPO gene AG/AA genotype was approximately $7.3 \%$ higher than the GG genotype, indicating that MPO gene variation changed carotid artery IMT. Mateo et al (28) reported that the recent hypertension guidelines added carotid artery IMT as the marker of end organ damage. In particular, average IMT of the carotid artery could better evaluate AS. Hypertension is the main risk factor promoting AS occurrence and development, while stenosis caused by renal arteriosclerosis may cause secondary hypertension. Therefore, hypertension and AS have an interactional relationship. Hypertension and AS have similar arterial inflammatory pathological changes, and both cause inflammation and endothelial cell damage to the vascular wall (29). As the main risk factor of AS, hypertension is capable of quickening the occurrence and development of AS, while the relationship of MPO gene polymorphisms with carotid AS of EH patients is not still reported.

The morphology of common carotid artery is straighter, location is more superficial, and common carotid artery is more parallel to the skin surface. IMT is also easily measured, the measurement value is reliable and repeatability is good. Therefore, IMT may be widely used in the clinic. An epide- miological study (30) and an intervention test (31) have proven that the IMT of carotid artery is an important marker of AS by means of high-resolution ultrasound detection. Moreover, ultrasound detection of carotid IMT has been used to predict apoplexy and myocardial infarction (32). Many experiments, but not all, $(33,34)$ have proven that blood pressure plays an important role in the occurrence and development of IMT.

This study carried out fractional analysis of hypertension patients and showed that the IMT of the carotid artery and plaque frequency of EH patients significantly increased, and the genotype GG distribution frequency of patients in the AS group was higher compared to that of the non-AS group. In this study, it was found that IMT of the common carotid artery of EH patients of the AS group was thicker compared to that of the non-AS group, and there was a significant difference for frequency distribution between the GG and AA+GA genotypes. The incidence rate of hypertension patients with the GG genotype was high. In addition, further comparison of carotid plaques of hypertension patients showed that the carotid plaque incidence rate of the MPO gene GG genotype patients in the AS group increased. Thus, it may be observed that carotid AS is related to MPO gene polymorphism.

In conclusion, MPO gene polymorphisms in AS are closely related to the occurrence and development of cardiovascular disease. Although our study suggests that hypertension genetic susceptibility of Chinese patients is related to MPO gene polymorphisms, research results in different ethnicities and populations may be inconsistent. This study analyzed the relationship of EH and MPO gene polymorphisms. As there are fewer genotypes, it is necessary to define the association of genotypes with EH by analyzing larger sized samples.

\section{References}

1. Ross R: Atherosclerosis-an inflammatory disease. N Engl J Med 340: 115-126, 1999.

2. Babior BM: Phagocytes and oxidative stress. Am J Med 109: 33-44, 2000.

3. Berliner JA and Heinecke JW: The role of oxidized lipoproteins in atherogenesis. Free Radic Biol Med 20: 707-727, 1996.

4. Heinecke JW: Oxidants and antioxidants in the pathogenesis of atherosclerosis: implications for the oxidized lowdensity lipoprotein hypothesis. Atherosclerosis 141: 1-15, 1998.

5. Rosenfeld ME: Inflammation, lipids, and free radicals: lessons learned from the atherogenic process. Semin Reprod Endocrinol 16: 249-261, 1998.

6. Steinberg D: Low density lipoprotein oxidation and its pathobiological significance. J Biol Chem 272: 20963-20966, 1997.

7. O'Brien PJ: Peroxidases. Chem Biol Interact 129: 113-139, 2000.

8. Nicholls SJ and Hazen SL: The role of myeloperoxidase in the pathogenesis of coronary atery disease. Jpn J Infect Dis 57: S21-S22, 2004

9. Eiserich JP, Baldus S, Brennan ML, Ma W, Zhang C, Tousson A, Castro L, Lusis AJ, Nauseef WM, White CR and Freeman BA: Myeloperoxidase, a leukocyte-derived vascular NO oxidase. Science 296: 2391-2394, 2002.

10. Sugiyama S, Kugiyama K, Aikawa M, Nakamura S, Ogawa H and Libby P: Hypochlorous acid, a macrophage product, induces endothelial apoptosis and tissue factor expression: involvement of myeloperoxidase-mediated oxidant in plaque erosion and thrombogenesis. Arterioscler Thromb Vasc Biol 24: 1309-1314, 2004.

11. Meuwese MC, Stroes ES, Hazen SL, van Miert JN, Kuivenhoven JA, Schaub RG, Wareham NJ, Luben R, Kastelein JJ, Khaw KT and Boekholdt SM: Serum myeloperoxidase levels are associated with the future risk of coronary artery disease in apparently healthy individuals the EPIC-Norfolk Prospective Population Study. J Am Coll Cardiol 50: 159-165, 2007. 
12. Tang WH, Brennan ML, Philip K, Tong W, Mann S, Van Lente F and Hazen SL: Plasma myeloperoxidase levels in patients with chronic heart failure. Am J Cardiol 98: 796-799, 2006.

13. Tang WH, Tong W, Troughton RW, Martin MG, Shrestha K, Borowski A, Jasper S, Hazen SL and Klein AL: Prognostic value and echocardiographic determinants of plasma myeloperoxidase levels in chronic heart failure. J Am Coll Cardiol 49: 2364-2370, 2007.

14. Li Y, Qin Y, Wang ML, Zhu HF and Huang XE: The myeloperoxidase-463 $\mathrm{G}>\mathrm{A}$ polymorphism influences risk of colorectal cancer in southern China: a case-control study. Asian Pac J Cancer Prev 12: 1789-1793, 2011.

15. Podrez EA, Poliakov E, Shen Z, et al: A novel family of atherogenie oxidized phospholipids promotes macrophage foam cell formation via the scavenger receptor CD36 and is enriched in atherosclerotic lesions. J Biol Chem 277: 38517-38523, 2002.

16. Puato M,Palatini P,Zanardo M, Dorigatti F, Tirrito C, Rattazzi M and Pauletto P: Increase in carotid intima-media thickness in grade I hypertensive subjects: white-coat versus sustained hypertension. Hypertension 51: 1300-1305, 2008.

17. Skuladottir H, Autrup H, Autrup J, Tjoenneland A, Overvad K, Ryberg D, Haugen A and Olsen JH: Polymorphisms in genes involved in xenobiotic metabolism and lung cancer risk under the age of 60 years. A pooled study of lung cancer patients in Denmark and Norway. Lung Cancer 48: 187-199, 2005.

18. Hung RJ, Boffetta P, Brennan P, Malaveille C, Gelatti U,Placidi D, Carta A, Hautefeuille A and Porru S: Genetic polymorphisms of MPO, COMT, MnSOD, NQO1, interactions with environmental exposures and bladder cancer risk. Carcinogenesis 25: 973-978, 2004.

19. Ahn J, Gammon MD, Santella RM, Gaudet MM, Britton JA, Teitelbaum SL, Terry MB, Neugut AI, Josephy PD and Ambrosone CB: Myeloperoxidase genotype, fruit and vegetable consumption, and breast cancer risk. Cancer Res 64: 7634-7639, 2004.

20. Zhu H, Yang L, Zhou B, Yu R, Tang N and Wang B: Myeloperoxidase G-463A polymorphism and the risk of gastric cancer: a case-control study. Carcinogenesis 27: 2491-2496, 2006.

21. Asselbergs FW, Reynolds WF, Cohen-Tervaert JW, Jessurun GA and Tio RA: Myeloperoxidase polymorphism related to cardiovascular events in coronary artery disease. Am J Med 116: 429-430, 2004

22. Sugiyama S, Okada Y, Sukhova GK, Virmani R, Heinecke JW and Libby P: Macrophage myeloperoxidase regulation by granulocyte macrophage colony-stimulating factor in human atherosclerosis and implications in acute coronary syndromes. Am J Pathol 158: 879-891, 2001.

23. Mäkelä R, Karhunen PJ, Kunnas TA, Ilveskoski E, Kajander OA, Mikkelsson J, Perola M, Penttilä A and Lehtimäki T: Myeloperoxidase gene variation as a determinant of atherosclerosis progression in the abdominaland thoracic aotra: an autopsy study. Lab Invest 83: 919-925, 2003.
24. Nikpoor B, Tureeki G, Fournier C, Théroux P and Rouleau GA: A functional myeloperoxidase polymorphie variant is associated with coronary artery disease in French-Canadians. Am Heart J 142: 336-339, 2001.

25. Exner M, Minar E, Mlekusch W, Sabeti S, Amighi J, Lalouschek W, Maurer G, Bieglmayer C, Kieweg H, Wagner O and Schillinger M: Myeloperoxidase predicts progression of carotid stenosis in states of low high-density lipoprotein cholesterol. J Am Coll Cardiol 47: 2212-2218, 2006.

26. Hoy A, Trégouët D, Leininger-Muller B, Poirier O, Maurice M, Sass C, Siest G, Tiret L and Visvikis S: Serum myeloperoxidase concentration in a healthy population: biological variations, familial resemblance and new genetic polymorphisms. Eur J Hum Genet 9: 780-786, 2001.

27. Mäkelä R, Loimaala A, Nenonen A, Mercuri M, Vuori I, Huhtala H, Oja P, Bond G, Koivula T and Lehtimäki T: The association of myeloperoxidase promoter polymorphism with carotid atherosclerosis is abolished in patients with type 2 diabetes. Clin Biochem 41: 532-537, 2008.

28. Mateo I, Morillas P, Quiles J, Castillo J, Andrade H, Roldán J, Agudo P and Bertomeu-Martínez V: What measure of carotid wall thickening is the best atherosclerotic loading score in the hypertensive patient: maximum or mean value? Rev Esp Cardiol 64: 417-420, 2011 (In Spanish).

29. Grundy SM: Inflammation hypertension and the metabolic syndrome. JAMA 290: 3000-3002, 2003.

30. de Groot E, Hovingh GK, Wiegman A, Duriez P, Smit AJ, Fruchart JC and Kastelein JJ: Measurement of arterial wall thickness as a surrogate markerfor atherosclerosis. Circulation 109 (23 Suppl 1): III33-III38, 2004.

31. Wang JG, Staessen JA, Li Y, Van Bortel LM, Nawrot T, Fagard R, Messerli FH and Safar M: Carotid intima-media thickness and antihypertensive treatment: a meta-analysis of randomized controlled trials. Stroke 37: 1933-1940, 2006.

32. O'Leary DH, Polak JF, Kronmal RA, Manolio TA, Burke GL and Wolfson SK Jr: Carotid-artery intima and media thickness as a risk factor for myocardial infarction and stroke in older adults. Cardiovascular Health Study Collaborative Research Group. N Engl J Med 340: 14-22, 1999.

33. Lakka TA, Salonen R, Kaplan GA and Salonen JT: Blood pressure and the progression of carotid atherosclerosis in middleaged men. Hypertension 34: 51-56, 1999.

34. Lemne C, Jogestrand T and de Faire U: Carotid intima-media thickness and plaque in borderline hypertension. Stroke 26: 34-39, 1995. 